"Regulation XIX.--The Medical Experimental Committee shall meet occasionally for the purpose of suggesting and trying experiments, with a view to throw additional light on the animal economy, and to discover the effects of medicines upon different animals, to be procured for that particular purpose; and this Committee shall from time to time make reports of their proceedings to the Council."

Will Mr. Spooner, as Principal of the Veterinary College in London, favour the world with the proceedings of the Com. mittee of Transaction and of the Experimental Committee?

The science of pathology greatly needs comparative illustra. tion. This was the great idea of John Hunter, one of the founders of the London Veterinary College. Certain it is that well-conducted experiments on living animals have been, and must ever be, one of the most fertile sources of original information to the practical medical philosopher. Yet how many of our best experimenters apply at the London Veterinary College, year after year, for the purpose of conducting inquiries, only to be met with refusal.

Would it be unreasonable to call in question the wisdom and high-mindedness of anyone who, being a party to the neglect of such regulations as those inspired by the genius of Hunter, quoted above, strove to make capital of public philanthropy by stigmatizing the abuse of vivisections on the Continent?

I have the honour to be, Sir, your obedient servant, J. Sampson Gamger

Broad-street, Birmingham Surgeon to the Queen's Hospital, \&c. Oet. 22 nd 1860

\section{NEW METHOD OF REDUCING SIRANGULATED HERNIA.}

Tho the Editor of THE LANCET.

SIR, - I read with considerable interest in your journal of the 20 th inst. a paper on the above subject, and I can testify to the efficacy of the means therein recommended by $\mathrm{Mr}$. Jessop, having during the course of several years had many cases of a similar nature come under my observation, of one of which I send you the following account:-

Some years ago I was summoned one night to a man between fifty and sixty years of age, who was employed upon the estate of Sir H. Meux, at 'Theobald's park, in Hertfordshire, and whom I found labouring under strangulated hernia in the right inguinal region, of some hours' duration. I endeavoured, but without success, to effect reduction by the usual methods. Wishing to save my patient, if possible, from a painful operation, I then drew him to the foot of the bed, and placed each leg over the shoulders of two of his fellow workmen who were within call. His body being completely inverted, and supported by the flexion of his head and shoulders, and the fibres of the abdominal muscles having become relaxed by inversion, $\bar{I}$ succeeded in a few minutes, by careful manipulation, in completely reducing an intensely painful, hard, and strangulated hernia.

Trusting that this method of overcoming this dangerous surgical disease may, by being early resorted to, render more serious operative measures seldom necessary,

I remain, Sir, your obedient servant,

Chandos-street, Strand, Oct, 1860. JoseUA WATKINS, M.R.C.S,

\section{POISONING BY "DR. LOCOCK'S PULMONIC WAFERS." \\ To the Editor of THe Lancet.}

Srr, - On the 18th ultimo, at eight o'clock A.M., I was called to see William _ aged four years and a half, who was represented as very ill from having eaten nearly a whole box of Dr. Locock's pulmonic wafers, containing about twenty-four lozenges. I saw him twenty minutes after; he was then suffering from great giddiness; unable to walk or even stand without assistance; drowsiness and stupor, verging wpon coma. The eyelids were half closed; the pupils contracted to the size of a pin's head; the breathing slow; the circulation depressed; the skin covered with sweat; the extremities cold; and there was urgent thirst; - in short, the little fellow was suffering from narcotic poisoning. Fortunately, he had vomited freely very soon after having eaten the lozenges, Stimulating emetics, with copious draughts of warm water, were at once administered, which acted well. Hot applications to the feet and legs, with friction, were had recourse to. Streams of cold water were also poured upon the head, which had a powerful effect in arousing the patient and restoring him to consciousness. Strong coffee, with diffusible stimulants, were freely 120 given; also small quantities of tincture of belladonna. But at last it was found necessary to have him removed to the garden, and there walked up and down, and amused by his companions. From this time the symptoms began to assume a more favourable aspect. Towards evening he seemed out of danger, slept well during the night, and in the morning all traces of poisoning had disappeared.

These wafers evidently contain some powerful narcotic in. gredient, injurious if taken in large quantities, and highly dangerous to children. Such a hint is not given in the printed directions attached to each box of these lozenges. Why? I remain, Sir, yours faithfully,

Stranraer, Wigtonshire, Oct. 1860.

David Easton, M.D.

** Our correspondent might also ask, Why do the pro. prietors of this quack medicine abuse the name of an honourable and distinguished member of the medical profession?ED. L.

\section{MORTALITY IN CHURCH-LANE, ST. GILES'S.} To the Editor of THE LANCET.

SIR,-A paragraph in your journal of the 13 th inst. quotes some statisties of the mortality in Church-lane, St. Giles's. Will you oblige me by stating that the mortality there referred to is that of the years 1839-14, the figures being extracted from a paper by Mr. Horace Mann, communicated to the Statistical Society in 1848. Since that period very great improvement has been effected in this locality by the operation of the Common Lodging-honses Act, and of the Metropolis Local Management Act, under which medical officers of health and sanitary inspectors hold their powers. The statistics of twenty years ago have, therefore, only an historical bearing upon present facts. Indeed, at this moment, Church-lane and its environs are in an unprecedentedly healthy condition. The extent and cause of the improvement are indicated in the following extract from my last annual report:-

"In none of the ten sub-divisions of St. Giles's was the im. provement in the public health during 1859 so striking as in the locality which includes Church-lane. In 1857 and 1858 the deaths here were steady, at $2 \lessgtr 1$ and 283 per ten thousand residents; in 1859 they sank to 222 . This amendment affected all the diseases which are most characteristic of St. Giles's: fewer children died; there was less zymotic mortality; consumption and lung-diseases had fewer victims. In Church-lane and its courts alove the actual deaths in 1859 were but twentynine against forty-eight in the year that went before. Who can doubt the cause? In 1858 and the beginning of 1859 vigorous steps were taken to improve this locality, by securing better ventilation to the houses and rooms, cleaner privies and ampler water-supply: over-crowding was carefully prevented. One of the courts most affected by these measures was Kennedy court. In 1858 six people died here; two from fever, one from erysipelas, another from consumption, and two were chil dren under two years of age. In 1859 there was not a single death. In 1853 thirteen people from Church-lane and its purlieus died in the workhouse; in 1859, five only. Who will calculate for the economist the money-value of these sanitary measures?"

I trust that these facts may be of some comfort to your readers, who have no doubt been sighing for some days over an interesting bit of antiquarian statistics.

I am, Sir, your obedient servant,

George Buchainan,

Gower-street, October, 1860

$$
\text { Medical Officer of Health for St. Giles's District. }
$$

\section{THE DELUSION OF SPIRITUALISM. To the Editor of THE LANCET.}

Str, - I have with much pleasure read your admirable article on Spiritualism. While maintaining the same views, I have often met with the assertion that Sir D. Brewster and the Bishop of Oxford are believers, and therefore there must be something more than humbug in it. Can this be true?

Hastings, Oct. 1860 I am, Sir, faithfully yours,

D. H. G.

WaNTED, AN EDitor.-The difficulties in the way of conducting the British Medical Journal in such a manner as to please two thousand proprietors, have culminated in the resignation of the Editorship by Dr. Wynter. The Association advertizes for an Editor to supply the vacancy. 